\title{
A Simulation-based Analysis of the Influence of Renewables on the Spanish Electricity Prices
}

\author{
Diego Azofra' ${ }^{1}$,Emilio Jiménez ${ }^{1 *}$, Eduardo Martínez-Cámara ${ }^{1}$, Julio Blanco ${ }^{1}$, \\ Juan Ignacio Latorre ${ }^{2}$ \\ ${ }^{1}$ University of La Rioja. High Technical School of Industrial Engineering. Departments of Electrical Engineering and \\ Mechanical Engineering. San José de Calasanz 31, 26004 Logroño (La Rioja). Spain; *emilio.jimenez@unirioja.es \\ 2Public University of Navarre, Department of Mechanical, Energy and Materials Engineering, Campus of Tudela, \\ 31500 Tudela (Navarre), Spain; juanignacio.latorre@unavarra.es
}

SNE 28(4), 2018, 191 - 196, DOI: 10.11128/sne.28.tn.10449 Received: November 27, 2018; Revised December 8, 2018;

Accepted: December 10, 2018

SNE - Simulation Notes Europe, ARGESIM Publisher Vienna ISSN Print 2305-9974, Online 2306-0271, www.sne-journal.org

Abstract. Spain is at the forefront of renewable energy worldwide with a great integration level in its generation mix. This has put Spain in the situation that other countries that support renewable energy will be in a short-medium term. However active measures to support renewable energy have been losing strength in recent times seeking to reduce the deficit. On the one hand, the bonus for each technology is different and, on the other hand, their integration level in the mix, and thus its influence on the Pool, is uneven. This work aims to provide information and conclusions about the actual economic impact of each renewable technology on the pool and the electricity tariff for the Spanish case. For doing so, simulation and artificial intelligence techniques are applied in order to model the energy pool and simulate the electricity prices in five fictitious scenarios that suppress out of the generation mix, respectively, wind, photovoltaic, biomass, small hydraulic, and solar thermal. This way, based on the simulation, and ex-post analysis can be developed in order to obtain conclusions and knowledge, useful for other countries as well as for future decision making in the Spanish power system.

\section{Introduction}

Spain is at the forefront of renewable energies worldwide, with a great integration level of them in its generation mix. This has put Spain in the situation which the other countries supporting renewable energies will be in a short-medium term. However active policies to support renewable energy have been losing strength in recent times, seeking to reduce the deficit. This fact, coupled with the significant rising experienced by the electricity bill lately, have made ordinary people and society in general to belief that renewables technologies are expensive for the system and constitute the main cause for that rising.

It is true that renewable generation technologies have not been, up to date, competitive enough to challenge the traditional thermoelectric power plants, which has made them earn bonuses from generation. But renewables have in turn benefits for the system as their ranking preference in the energy auction gets the most expensive technologies out of the pool, lowering thus the electricity prices. That works in practice in a very uneven way depending on the type of renewable energy. This happens because, on the one hand, the bonus for each technology is different and, on the other hand, their integration level in the mix, and thus its influence on the pool, is disparate.

This paper presents a global view of the effects of different renewable energy sources on the electricity pool [1] combining and complementing the analysis of the effects of five renewable sources: wind, photovoltaic, biomass, small hydraulic, and solar thermal. The ex-post economic analysis of photovoltaic power in the Spanish grid was analysed in [2] by modelling alternative scenarios. The analysis of wind power merit-order and feed-intariffs effect by a variability analysis of the Spanish electricity market was developed in [3], while [4] compared the influence of photovoltaic and wind power on the Spanish electricity prices by means of artificial intelligence techniques and [5] did a similar comparison of biomass, solar-thermal and small hydraulic power. Finally [6] presented the economical-environmental impact analysis of subsidised renewable energy sources for electricity (RES-E) in the Spanish system. Other works have continued with this analysis of the renewable energy policy, the impact of wind generation on the spot market 
electricity pricing, and the support policies and merit order effect, such as [7-9].

In this work artificial intelligence techniques (algorithm M5P) are applied in order to model the energy pool cassation process. Once, the model has been created, it is time to simulate the new electricity price in five fictional scenarios that suppress wind, photovoltaic, biomass, small hydraulic, and solar thermal, respectively, out of the generation mix. Taking into account the price reduction produced for renewables as well as the bonus received, it is determined, for each renewable technology, whether it is beneficial or in deficit for the system. To go a step further and extrapolate the influence of renewable energies over the pool to the tariff or charges to be paid by the final consumer, the low voltage most common tariff, known as TUR, is recalculated for the above-mentioned scenarios. From this study it will be concluded that, with the analysed Spanish renewable policy, wind, biomass and small hydraulic power were beneficial while the photovoltaic and solar thermal technologies were economically deficient for the system, as well as for the electricity tariff.

\section{Methodology and Scope}

The main objectives of this work are:

- Apply artificial intelligence techniques (M5P algorithm - tree model) for the simulation of the electricity matching process in the Pool which have proved really accurate.

- Determine the economic influence of the main renewable technologies (wind, solar, biomass, small hydraulic and solar thermal) on the price reduction in the Spanish Pool.

- Taking into account the price reduction produced for renewables as well as the bonus received, determine for each renewable technology, whether it is beneficial or in deficit for the system.

That is, we want to determine, using an ex-post analysis, the economic influence of the major renewable technologies eligible for bonus (wind, photovoltaic, biomass, small hydraulic and solar thermal) on the Spanish electricity grid.

For doing so, five fictional scenarios, which suppress the Spanish generation mix each of the aforementioned technologies respectively have been created:

- SCENARIO A: Real generation mix excluding generation from wind technology.

- SCENARIO B: Real generation mix excluding the generation from photo-voltaic technology.

- SCENARIO C: Real generation mix, excluding generation from biomass.

- SCENARIO D: Real generation mix, excluding generation from thermoelectric solar technology.

- SCENARIO E: Real generation mix, excluding generation from small-hydraulic technology.

The balance in the system is restored in the model by filling the gap of renewable generation in each scenario by combined cycle and coal thermal power plants, being the only ones capable of acting as back-up power plants. The establishment of the new equilibrium in the system will provide a new pool price lower than the original (real mix with all technologies).

\section{Simulation Model}

Once the scenarios have been defined, it is necessary to generate a model that simulates the matching of the price of energy, thus determining the inversely proportional relationship between the $\%$ of integration of renewables in the Pool and the price of the resulting energy [2-6].

In order to reduce the dispersion resulting from the dispersion chart of the pool's price and the level of integration in the renewable mix, it is imperative to carry out a multivariate analysis that takes into account parameters such as generation by technology, capacity available by technology ..., and that in turn throw light on such dispersion of points.

Several prediction algorithms have been tested using WEKA in order to determine its accuracy to predicting the final price of energy in the Pool, based on the attributes. Several ones have presented a similar adjustment and correlation factor with respect to the database (M5P, Metabagging Reptree, M5rules, and IBK lazy) [1]. The M5P algorithm has been chosen, which allows us to obtain hidden knowledge of the matching process thanks to the graphic visualization of the model tree.

Once a model that represents the Spanish electric Pool with sufficient precision is determined, the new resulting price is simulated in each scenario.

Taking into account that the bonus produces an increase in the cost of electricity tariff and their preference order in the electricity auction produces a drop in the energy prices matching in the Pool, it is considered that if the two factors are eliminated, the influence of each renewable technology on the system and the electricity tariff is determined. 


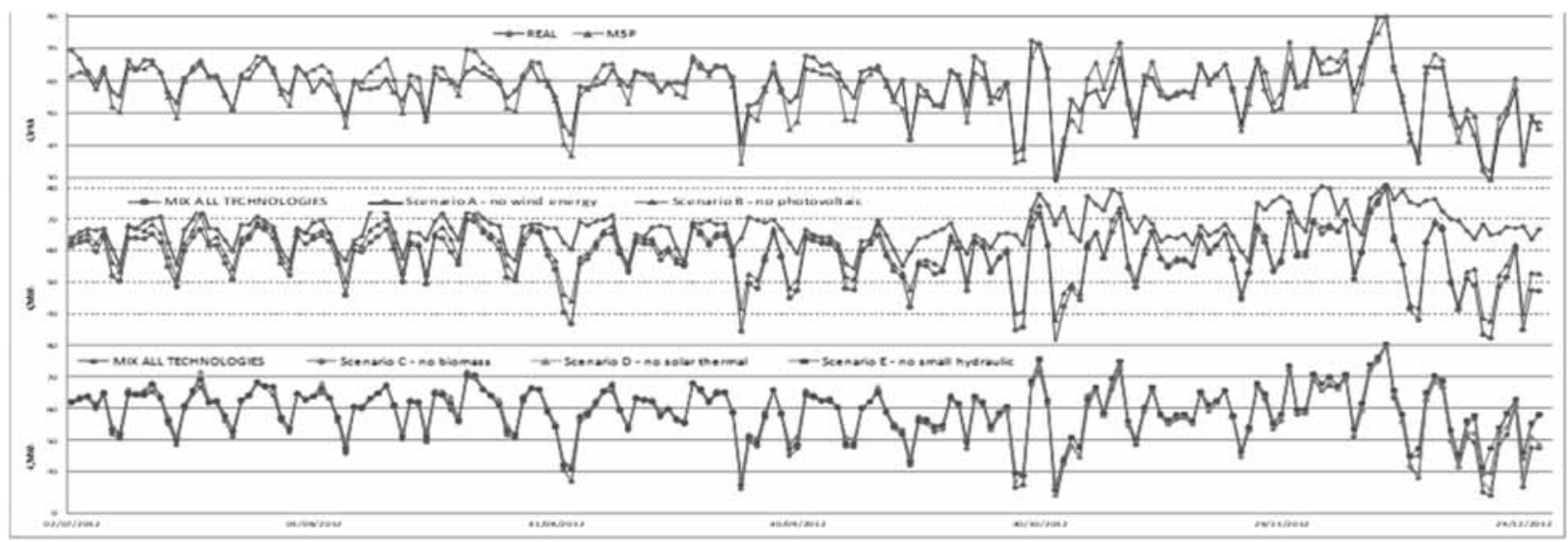

Figure 2. a) (upper graph) comparison between the final hourly price of real cassation (blue) and that obtained by the M5P prunned model (red), b) Comparison for each day of the final price obtained by the model for the scenario with all the technologies (red), scenario A without generation wind (blue) and B, without photovoltaic generation (green); c) comparison now with scenario C, without generation by biomass (blue), scenario D, without solar thermal generation (green) and scenario $\mathrm{E}$, without small-hydraulic generation (violet).

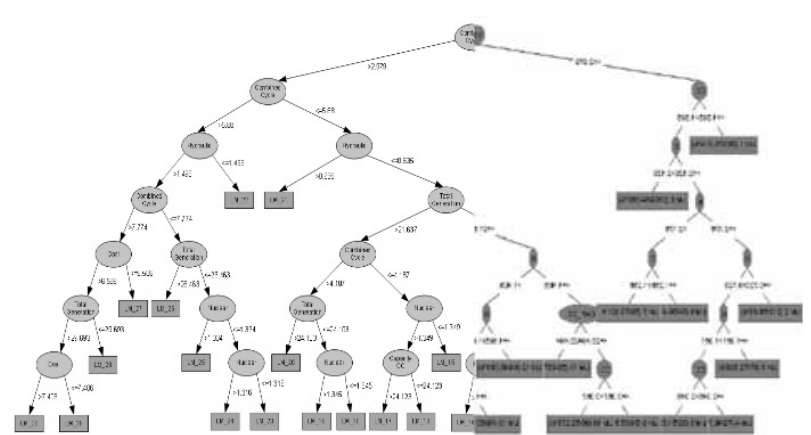

Figure 1. Model tree combining 2 different representation formats $[4,5]$.

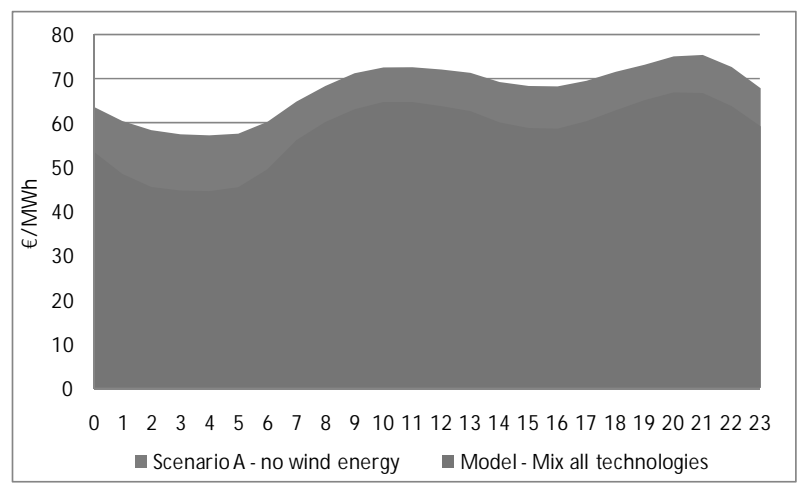

Figure 3. Final hourly prices obtained by the model for the real scenario vs. a scenario without wind generation.

The training database contains the schedule data of the variables shown in the previous point between January 1, and December 31, 2012 (the year selected for the ex-post analysis of this work). The calculations have been made by applying the cross-validation technique with an improvement of the holdout method.

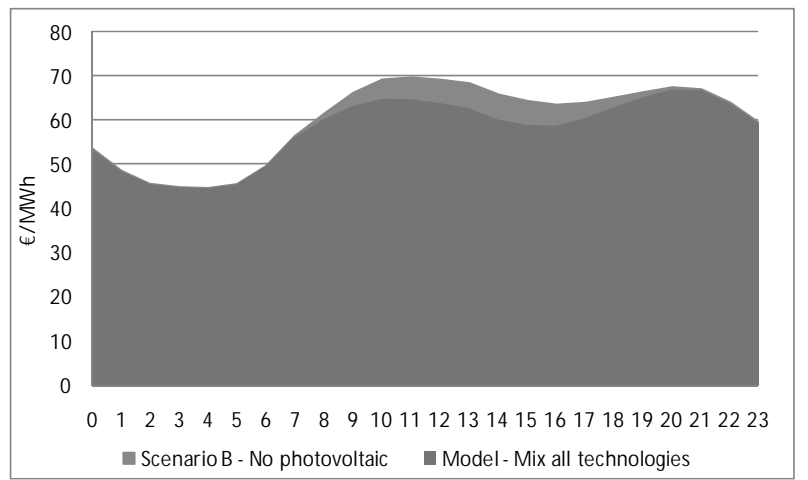

Figure 4. Final hourly prices obtained by the model for the real scenario vs. a scenario without photovoltaic generation.

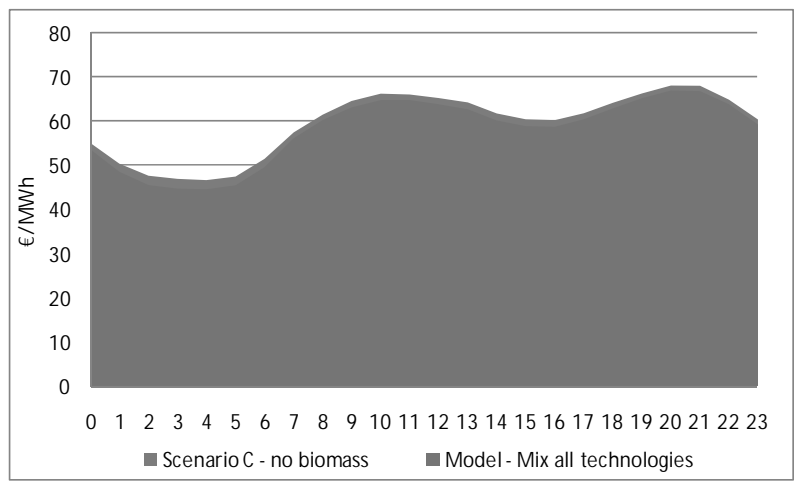

Figure 5. Final hourly prices obtained by the model for the real scenario vs. a scenario without biomass generation.

Once the model is trained, we have a model tree (Figure 1) that returns the MWh price based on the input variables used, and we will be able therefore to use it to determine the new pool price resulting in the five scenarios fictitious. 


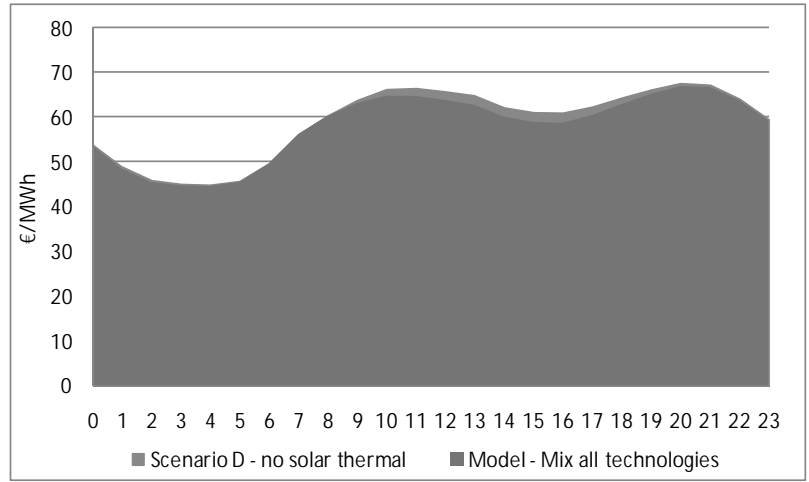

Figure 6. Final hourly prices obtained by the model for the real scenario vs. a scenario without solar thermal generation.

\section{Simulation Results: Economic Influence of Renewable Technologies}

Figure 2 represents the comparative [1] between the real case and the one obtained from the M5P algorithm (upper graph) and compares the hourly price of the electric power obtained by the model for the real case vs. the price obtained by the model for each of the scenarios for every day of a semester (wind and photovoltaic in the intermediate graph, and biomass, solar thermal and small hydraulic in the lower graph).

The results shown for a day are represented in figures 3 to 7 , which show that the scenarios without wind and photovoltaic generation return higher Pool matching prices. In relation to wind energy, the biggest difference is produced at night because demand decreases and wind generation remains relatively constant, which means that there is virtually no remaining generation to be covered by thermal power plants.

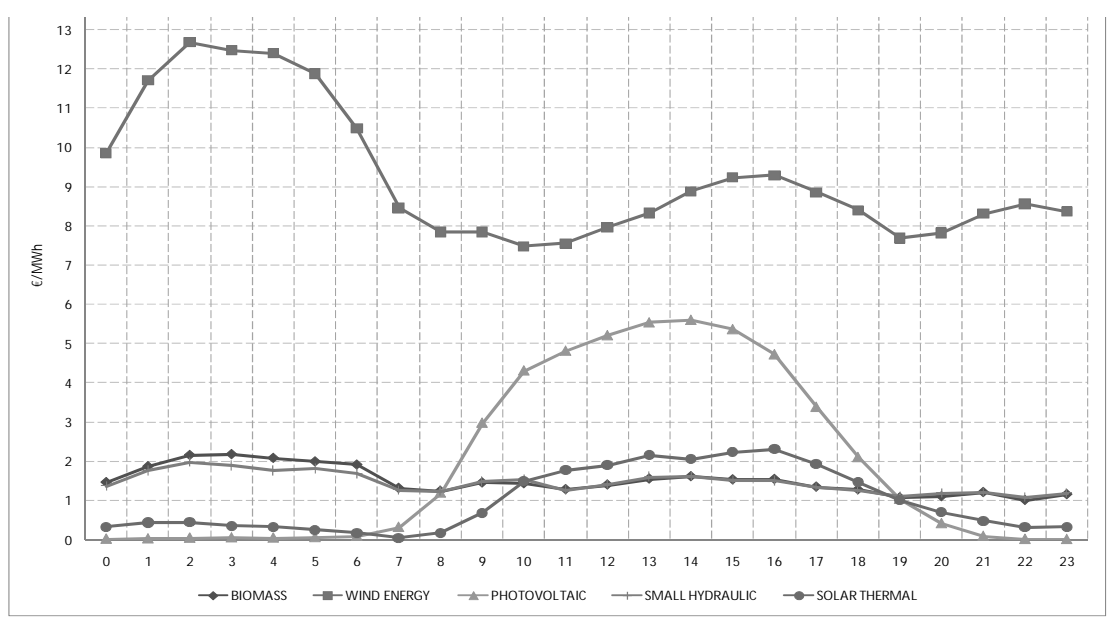

Figure 8. Decrease in the price of the energy produced by each technology per

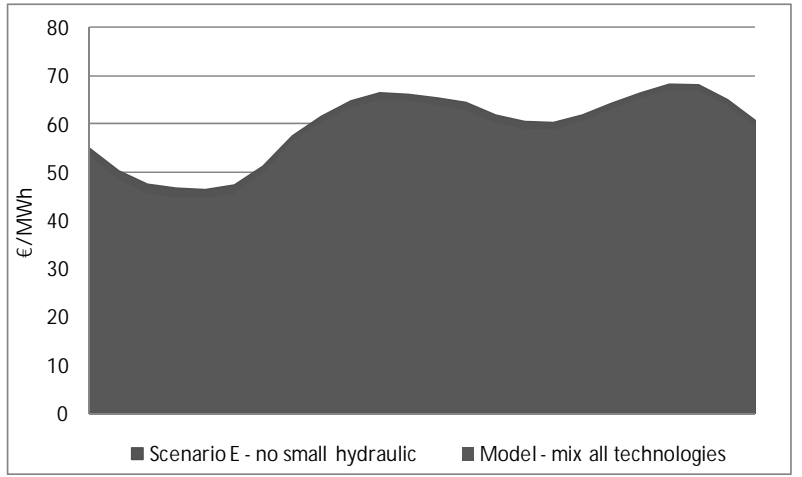

Figure 7. Final hourly prices obtained by the model for the real scenario vs. a scenario without small hydraulic generation.

With regard to photovoltaic energy, the generation curve during the day can be clearly observed, obtaining a maximum around 14:00 (12:00 in solar time in summer time) coinciding with the highest solar radiation over the country. The scenarios without electricity generation through biomass, solar thermoelectric or small hydraulic return higher Pool matching prices, which confirms again that the preference of order in the auction of the premium renewables generates a decrease in the final price of the auctioned energy. Figure 8 represents the decrease in the price of the energy produced by each technology individually for the day type.

\section{Conclusions}

Below are shown the main contributions made throughout this work as well as the results thereof.

i) The application of artificial intelligence techniques (Algorithm MP5 - model generation trees) to simulate the process of price cassation in the Pool, based on the levels of integration of each technology in the generation mix, have stated that:

- Wind power received bonuses for $€ 2037$ million, which caused a reduction of the average weighed price in the Pool of $9.10 € / \mathrm{MWh}$, generating as a whole a net saving for the grid of $€ 364.0$ million.

- Photovoltaic energy received bonuses of $€ 2610.7$ million, causing a reduction of the average weighed price in the Pool of $2.18 € / \mathrm{MWh}$, generating as a whole a net cost for the system of $€ 2034$.1 million. 
- The biomass for power generation received bonuses of $€ 344.0$ million, causing a reduction of the average weighed price in the Pool of $1.48 € / \mathrm{MWh}$, generating as a whole a net saving to the system of $€ 50.7$ million.

- Thermo-electric solar energy received bonuses of $€ 926.9$ million, causing a reduction of the average weighed price in the Pool of $1.05 € / \mathrm{MWh}$, generating as a whole a net cost for the system of $€ 648.2$ million.

- Energy from small-hydraulic power plants received bonuses of $€ 184.1$ million, causing a reduction of the average weighed price in the Pool of $1.45 € / \mathrm{MWh}$, generating as a whole a net saving for the system of $€ 200.6$ million.

ii) Going a step further and extrapolate the influence of renewable energies over the Pool to the tariff or charges to be paid by the final consumer in the year 2012, thus backing up the lack of related scientific literature up this moment, it has been concluded that:

- The wind power from the generation mix would have meant an extra cost for the average consumer in the TUR (Tariff of Last Resource) of $€ 1.95$ in the electricity bill. That is, wind power caused a $0.28 \%$ drop in the Tariff of Last Resource.

- To exclude photovoltaic energy from the generation mix would have meant a saving for the average consumer in the TUR of $€ 38.82$ in the electricity bill. That is, photovoltaic energy caused a $5.95 \%$ increase in the Tariff of Last Resource.

- To exclude biomass from the generation mix would have meant a cost for the average consumer in the TUR of $€ 0.12$ in the electricity bill. That is, biomass caused a $0.02 \%$ drop in the Tariff of Last Resource.

- To exclude solar thermo-electrical energy form the generation mix, would have meant a saving for the average consumer in the TUR of $€ 12.39$ in the electricity bill. That is, solar thermo-electric energy caused a $1.82 \%$ increase in the Tariff of Last Resource.

- To exclude the energy from small-hydraulic power plants from the generation mix would have meant an extra cost for the average consumer in the TUR of $€ 3.01$ in the electricity bill for the year 2012. That is, small-hydraulic energy caused a $0.43 \%$ drop in the Tariff of Last Resource.

iii) A sensitivity analysis allows a further knowledge of the effects of renewables depending on the actual penetration of the renewable source. For this purpose, 111 scenarios have been analysed, ranging from zero penetration in the grid to a $110 \%$ of the real wind power generation of the year 2012. The conclusions are:
- Energy generation by means of wind power technology would have been profitable to the grid as long as the generation level had been equal or higher than the of the $83 \%$ of the real generation.

- The worst wind power generation level, in economic terms, coincides with the $55 \%$ of the real generation. Under this scenario, the total cost overrun caused by wind power to the grid would have been of $€ 175.3$ million.

- The optimal wind power generation level, in economic terms, coincides with the $110 \%$ of the real generation. Under this scenario, the total saving produced by wind power over the system would have been of $€ 643.1$ million.

- Finally, and according to the variability of the wind map, if the year 2012 had been less windy, with a wind power generation of $90 \%$, the energy price reduction would have been of $7.42 € / \mathrm{MWh}$. On the contrary, if the year 2012 had been windier, with a generation of $110 \%$, the energy price reduction would have been of $10.94 € / \mathrm{MWh}$.

\section{Listings and Code}

The code used in this work, in concrete the tree model M5P and the VBA code for the sensitivity analysis of wind energy on the system, can be found on the Annex section of [1], which includes "Model tree - algorithm M5P”, "VBA code for sensitivity analysis of wind power on the system".

\section{References}

[1] Azofra D. Analysis of the influence of renewable energies on the price of electricity in Spain using Artificial Intelligence techniques/"Análisis de la influencia de las energías renovables sobre el precio de la electricidad en España mediante técnicas de Inteligencia Artificial", PhD Thesis, 2016, University of La Rioja https://dialnet.unirioja.es/servlet/tesis?codigo $=41546$

[2] Azofra D, Saenz-Díez JC, Martínez E, Jiménez E, Blanco J.). Ex-post economic analysis of photovoltaic power in the Spanish grid: Alternative scenarios. Renewable Energy, 95, 98-108, 2016. doi:10.1016/j.renene.2016.04.005.

[3] Azofra D, Jiménez E, Martínez E, Blanco J, SaenzDíez JC. Wind power merit-order and feed-in-tariffs effect: A variability analysis of the Spanish electricity market. Energy Conversion and Management, 83, 19-27. doi:10.1016/j.enconman.2014.03.057, 2014. 
[4] Azofra D, Martínez E, Jiménez E, Blanco J, Azofra F, Saenz-Díez JC. Comparison of the influence of photovoltaic and wind power on the Spanish electricity prices by means of artificial intelligence techinques. Renewable and Sustainable Energy Reviews, 42, 532-542. doi:10.1016/j.rser.2014.10.048.

[5] Azofra D, Martínez E, Jiménez E, Blanco J, SaenzDíez JC. Comparison of the influence of biomass, solar-thermal and small hydraulic power on the Spanish electricity prices by means of artificial intelligence techniques. Applied Energy, 121, 28-37, 2014. doi:10.1016/j.apenergy.2014.01.064.

[6] Azofra D, Jiménez E, Martínez E, Blanco J, SaenzDíez JC. Economical-environmental impact of subsidised renewable energy sources for electricity (RES-E) in the Spanish system. Energy for Sustainable Development, 29, 47-56, 2015. doi:10.1016/j.esd.2015.09.002.
[7] Blazquez J, Fuentes-Bracamontes R, Bollino CA, Nezamuddin $\mathrm{N}$. The renewable energy policy paradox. Renewable and Sustainable Energy Reviews, 82, 1-5, 2018. doi:10.1016/j.rser.2017.09.002

[8] Makalska T, Varfolomejeva R, Oleksijs R. The impact of wind generation on the spot market electricity pricing. Paper presented at the Proceedings - 2018 IEEE International Conference on Environment and Electrical Engineering and 2018 IEEE Industrial and Commercial Power Systems Europe, EEEIC/I and CPS Europe 2018, doi:10.1109/EEEIC.2018.8494539

[9] Lopes F, Sá J, Santana J. Renewable generation, support policies and the merit order effect: A comprehensive overview and the case of wind power in Portugal, 2018. doi:10.1007/978-3-319-74263-2_9 